\title{
Effect of Social Deprivation on the Stage and Mode of Presentation of Colorectal Cancer
}

\author{
Ahmed ELHadi, Sarah Ashford-Wilson, Stephanie Brown, Atanu Pal, Roshan Lal, Kamal Aryal \\ Department of General Surgery, James Paget University Hospital, Great Yarmouth, UK
}

Purpose: Based in a hospital serving one of the most deprived areas in the United Kingdom (UK), we aimed to investigate, using the Indices of Deprivation 2010, the hypothesis that deprivation affects the stage and mode of presentation of colorectal cancer.

Methods: All newly diagnosed patients with colorectal cancer presenting to a District General Hospital in the UK between January 2010 and December 2014 were included. Data were collected from the Somerset National Cancer Database. The effect of social deprivation, measured using the Index of Multiple Deprivation Score, on the stage and mode of presentation was evaluated utilizing Microsoft Excel and IBM SPSS ver. 22.0.

Results: A total of 701 patients (54.5\% male; mean age, 76 years) were included; 534 (76.2\%) underwent a surgical procedure, and 497 (70.9\%) underwent a colorectal resection. Of the patients undergoing a colorectal resection, $86(17.3 \%)$ had an emergency surgical resection. Social deprivation was associated with Duke staging $(P=0.09)$. The 90 -day mortality in patients undergoing emergency surgery was $12.8 \%$ compared to $6.8 \%$ in patients undergoing elective surgery $(\mathrm{P}=0.06)$. No association was found between deprivation and emergency presentation $(\mathrm{P}=0.97)$. A logistic regression analysis showed no increase in the probability of metastasis amongst deprived patients.

Conclusion: This study suggests an association between deprivation and the stage of presentation of colorectal cancer. Patients undergoing emergency surgery tend to have a higher 90-day mortality rate, although this was not related to deprivation. This study highlights the need to develop an individual measure to assess social deprivation.

\section{Keywords: Colorectal neoplasms; Socioeconomic status}

\section{INTRODUCTION}

Colorectal cancer (CRC) is the second most common cause of cancer death in the United Kingdom (UK) and the Western World. Previous population-based studies have shown a wide variation in survival worldwide. Survival in the UK remains inferior to that in other parts of the world, with a colon-cancer 5-year survival rate of $51.8 \%$ compared to $57 \%$ in Europe and $62 \%$ in

Received: February 27, 2016 - Accepted: July 23, 2016

Correspondence to: Ahmed ELHadi, M.B.B.S., MRCS

Department of General Surgery, James Paget University Hospital,

8 Woodpecker Lane, Norwich, Norfolk, NR4 7LS, United Kingdom

Tel: +441603-287583, Fax: +441603-287583

E-mail: ahmed.elhadi@gmail.com

(C) 2016 The Korean Society of Coloproctology

This is an open-access article distributed under the terms of the Creative Commons Attribution NonCommercial License (http://creativecommons.org/licenses/by-nc/4.0) which permits unrestricted non-

commercial use, distribution, and reproduction in any medium, provided the original work is properly cited.
Belgium, Germany and Iceland (EUROCARE 5) [1]. The 5-year CRC survival in Asia is approximately 60\% [2], and that in the United States (US) is as high as $64.9 \%$ [3].

The recently published UK National Bowel Cancer Audit report [4] showed a persistently high percentage (21\%) of CRC patients in England \& Wales presenting as an emergency. Several studies have shown that emergency surgery is associated with worse CRC outcomes [5-7] and higher mortality rates [8-12]. One US study reported a threefold increase in mortality in patients undergoing emergency colorectal resections in addition to lower anastomosis rates, higher complication rates and increased Intensive Care Unit admissions [13].

Several studies from the UK have suggested that social deprivation is associated with poor survival following surgery [14]. In addition, higher levels of advanced CRC and higher rates of postoperative mortality were observed amongst deprived patients [15]. US studies have reported similar findings, suggesting worse cancer outcomes amongst deprived populations with inappropriate levels 
of health insurance $[8,16]$. Suggested explanations for patients in deprived areas having worse survival rates compared to those in affluent areas include the advanced stage and nature of presentation, the mode of presentation, and poor screening [17-19].

This study is based in a government-funded (National Health Service) hospital serving a deprived population in the UK (according to the national census and English Indices of Deprivation 2010 [20]). We aimed both to test the hypothesis that socioeconomic status affects the Duke staging, as well as the mode of presentation (emergency vs. elective) of CRC to the healthcare service, and to assess the impact of deprivation on postoperative mortality.

\section{METHODS}

All newly diagnosed patients with CRC presenting between the 1st of January 2010 and the 31st of December 2014 to a District General Hospital in the UK were included. Data were collected from the Somerset National Cancer Database. The effect of social deprivation, measured based on the Index of Multiple Deprivation (IMD) score, on the stage and mode of presentation (elective vs. emergency) was evaluated by using a logistical regression analysis. Comparisons of association between deprivation and Duke staging, mode of presentation, mode of surgery, 30- and 90-day mortalities were made using chi-square statistics for trend and a univariate logistic regression. The data were analyzed using Microsoft Excel and IBM SPSS Statistics ver. 22.0 (IBM Co., Armonk, NY, USA).

The English Indices of Deprivation published by the UK Department for Communities and Local Government in 2011 [4] measures a broad spectrum of deprivation and combines 38 indicators that are grouped into seven domains (Fig. 1). IMD 2010 gives an overall measure of deprivation experienced by people living in a certain area for every Lower Layer Super Output Area in England. The IMD gives a score and categorizes the population into 5 quintiles, with the 1st quintile being the least deprived, and the 5 th quintile being the most deprived. The IMD scores and quintiles were calculated according to the patient's postcode at the

\begin{tabular}{l}
\hline IMD domains \\
\hline Income deprivation \\
Employment deprivation \\
Education, skills and training deprivation \\
Health deprivation and disability \\
Crime \\
Barriers to housing and services \\
Living environment deprivation \\
\hline
\end{tabular}

Fig. 1. Index of Multiple Deprivation (IMD) 2010 combines 7 domains. time of the diagnosis.

\section{RESULTS}

A total of 701 patients (54.5\% male, mean age, 76 years) were included, and the demographics of those patients are presented in Table 1. Of those 701 patients, 534 patients underwent a surgical procedure (76.2\%), and 497 patients (70.9\%) underwent a surgical resection, and of those undergoing a surgical resection, $86 \mathrm{pa}$ tients (17.3\%) had an emergency surgical resection (Table 2). Of the 701 patients, 179 patients $(25.6 \%)$ presented with metastatic CRC (M1 disease). No association was found between emergency resection and the 30-day mortality $(\mathrm{P}=0.10)$. The 90 -day mortality in patients undergoing emergency surgery was $12.8 \%$ compared to $6.8 \%$ in those undergoing elective surgery $(\mathrm{P}=0.06)$, as shown in Table 2.

An association was found between social deprivation and Duke staging $(P=0.09)$; this is shown in Fig. 2. No association was

Table 1. Summary of the patients' demographics and surgical resections performed

\begin{tabular}{lc}
\hline Variable & Value \\
\hline No. of patients & 701 \\
Sex, n (\%) & \\
Male & $382(54.5)$ \\
Female & $319(45.5)$ \\
Mean age (yr) & 76 \\
Mode of presentation & \\
\hline Emergency & 127 \\
\hline Elective & 574 \\
Total number of patients undergoing surgery & 534 \\
\hline Curative & 463 \\
\hline Palliative & 71 \\
Duke stage & \\
\hline A & 116 \\
B & 211 \\
C & 195 \\
D & 179 \\
Total resections performed & 497 \\
Anterior resection of rectum & 173 \\
Abdomino-perineal excision of rectum & 27 \\
Right hemicolectomy & 406 \\
\hline Left hemicolectomy & 10 \\
\hline Hartmann's procedure & 23 \\
\hline Other & \\
\hline & \\
\hline
\end{tabular}


Table 2. Summary of mode of surgical resection with 30 - and 90day mortality data

\begin{tabular}{lcc}
\hline Variable & No. (\%) & P-value \\
\hline Mode of resection & 497 & \\
Emergency & $86(17.3)$ & \\
Elective & $411(82.7)$ & \\
30-Day mortality & $25 / 497(5.0)$ & 0.10 \\
Emergency & $7 / 86(8.1)$ & \\
Elective & $18 / 411(4.4)$ & 0.06 \\
90-Day mortality & $39 / 497(7.8)$ & \\
Emergency & $11 / 86(12.8)$ & \\
Elective & $28 / 411(6.8)$ & \\
\hline
\end{tabular}

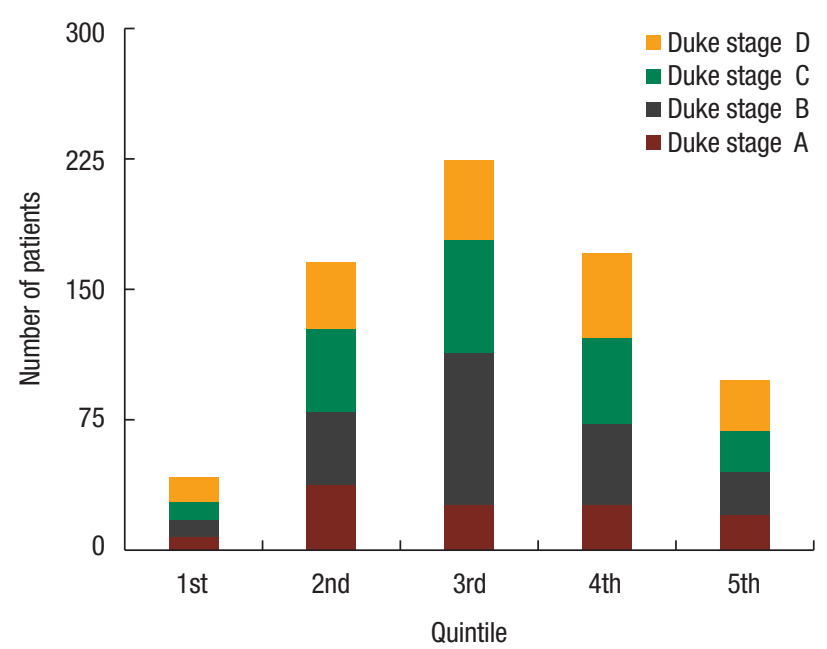

Fig. 2. Distribution of Duke staging within deprivation quintiles, with the 1st quintile being the least deprived, and the 5th quintile being the most deprived. The chi-square test showed no association between the quintile and the Duke stage $(\mathrm{P}=0.09)$.

found between deprivation and 30-day mortality $(\mathrm{P}=0.44)$ or 90 day mortality $(\mathrm{P}=0.49)$, as shown in Table 3 . Furthermore, no association was found between deprivation and presentation with M1 disease $(P=0.38)$, emergency presentation $(P=0.97)$ as shown in Table 4, or emergency resection $(\mathrm{P}=0.95)$, as illustrated in Fig. 3. The relationship between IMD and probability of metastasis could not be modeled well by using a logistic regression analysis $(\mathrm{P}=0.27)$ (Fig. 4).

\section{DISCUSSION}

The effect of social deprivation on CRC outcomes is a complex phenomenon. It is multifactorial and can be influenced by variations in healthcare systems worldwide, host factors, the biological behaviors of cancer in different populations, and the difficultly of using a single method of assessing the deprivation of an individ-
Table 3. Mode of surgery in relation to Index of Multiple Deprivation quintiles, with the 1st quintile being the least deprived, and the 5 th quintile being the most deprived

\begin{tabular}{lcccc}
\hline Quintile & $\begin{array}{c}\text { Emergency } \\
\text { surgery }\end{array}$ & $\begin{array}{c}\text { Elective } \\
\text { surgery }\end{array}$ & $\begin{array}{c}\text { Overall 30-day } \\
\text { mortality }\end{array}$ & $\begin{array}{c}\text { Overall 90-day } \\
\text { mortality }\end{array}$ \\
\hline 1st & $7(7.1)$ & $24(5.5)$ & $1(3.2)$ & $1(1.9)$ \\
2nd & $27(27.3)$ & $103(23.7)$ & $8(25.8)$ & $14(26.9)$ \\
3rd & $33(33.3)$ & $142(32.6)$ & $13(41.9)$ & $16(30.8)$ \\
4th & $19(19.2)$ & $105(24.1)$ & $8(25.8)$ & $16(30.8)$ \\
5th & $13(13.1)$ & $60(13.8)$ & $1(3.2)$ & $5(9.6)$ \\
Total & 99 & 434 & 31 & 52 \\
\hline
\end{tabular}

Values are presented as number (\%).

No association was observed between the quintile and 30-day mortality (chisquare test for trend; P-value $=0.44$ ) or 90 -day mortality (chi-square test for trend; P-value $=0.49$ ).

Table 4. Metastatic disease and emergency distribution in relation to the Index of Multiple Deprivation score, with the 1st quintile being the least deprived, and the 5th quintile being the most deprived

\begin{tabular}{lrccc}
\hline Quintile & Total & No. with M1 & $\begin{array}{c}\text { Emergency } \\
\text { resections }\end{array}$ & $\begin{array}{c}\text { Emergency } \\
\text { presentations }\end{array}$ \\
\hline 1st & 42 & $14(7.8)$ & 6 & $8(6.3)$ \\
2nd & 167 & $40(22.3)$ & 21 & $30(23.6)$ \\
3rd & 223 & $47(26.3)$ & 29 & $43(33.9)$ \\
4th & 172 & $50(27.9)$ & 18 & $28(22.0)$ \\
5th & 97 & $28(15.6)$ & 12 & $18(14.2)$ \\
Total & 701 & 179 & 86 & 127 \\
\hline
\end{tabular}

Values are presented as number (\%).

No association was observed between the quintile and presentation with $\mathrm{M} 1$ disease $(P=0.38)$, emergency presentation ( $P=0.97)$, or emergency resection $(P=0.95)$.

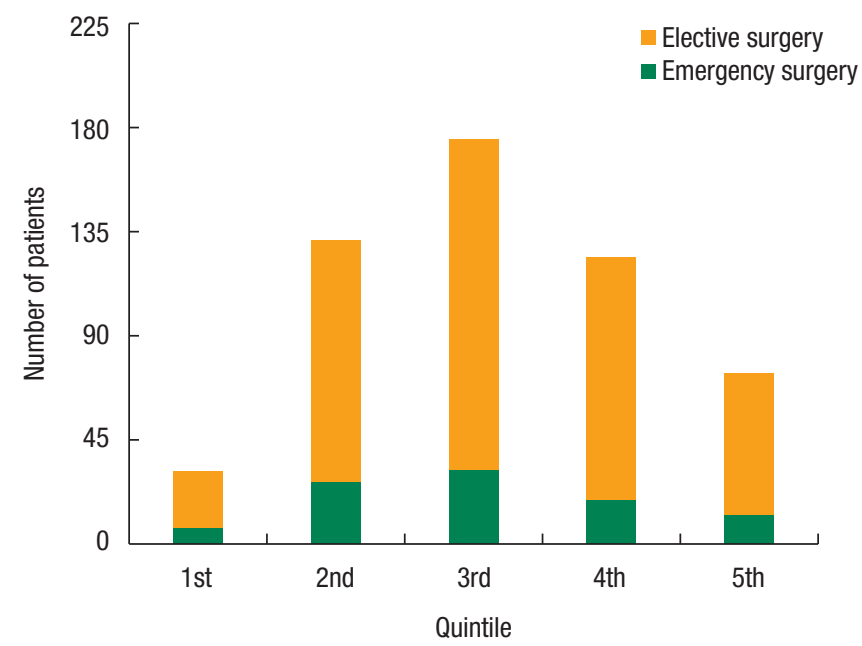

Fig. 3. Mode of surgery in relation to Index of Multiple Deprivation quintiles, with the 1st quintile being the least deprived and the 5th quintile being the most deprived. 
Logistic regression

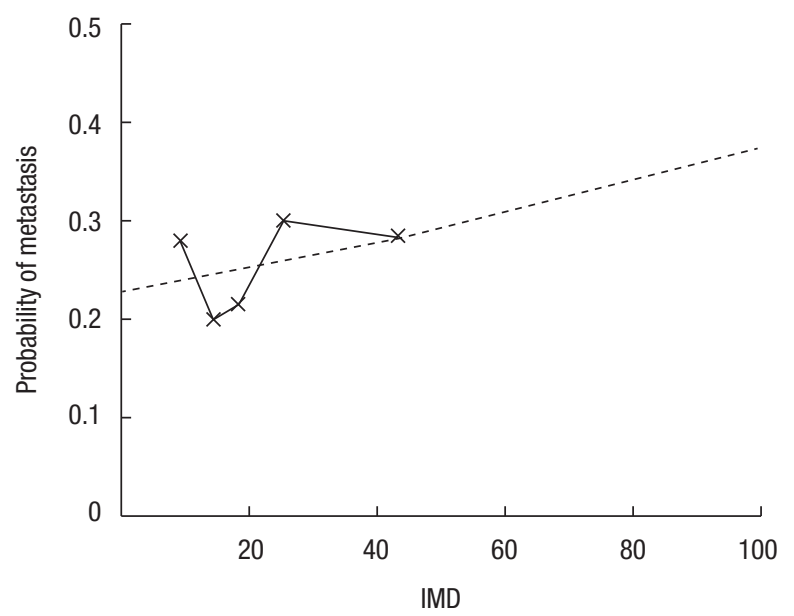

Fig. 4. Probability of metastasis in relation to Index of Multiple Deprivation (IMD) based on a logistic regression analysis.

ual. Our study demonstrates a link between social deprivation and the Duke stage of $C R C$ at presentation $(P=0.09)$. Although this finding does not have statistical significance, it is supported by the finding of Smith et al. [15], whose study had a high population with a similar design. Our study also suggests that patients undergoing emergency surgery have a higher 90 -day mortality rate $(\mathrm{P}=0.06)$, but this result did not appear to be influenced by deprivation $(\mathrm{P}=0.49)$. Interestingly, despite the advanced nature of disease amongst the more deprived patients, this was not reflected in the metastatic CRC (M1) stage, which could be due to the small sample size, the complexity of assessing the deprivation on an individual basis, and/or tumor-specific host factors affecting the behavior and progression of cancer cells. We did not demonstrate an association between deprivation and the mode of presentation or the mode of surgery, and these findings are supported by those of Hole and McArdle in a Scotland-based study [14].

Smith et al. [15] investigated the effect of deprivation on CRC patients having surgery in England and Wales and demonstrated that deprivation was an independent risk factor for length of hospital stay and was associated with a higher postoperative mortality. They used the Townsend score, which was first published by Townsend in 1988 [21] and is composed of 4 main variables (unemployment, overcrowding, noncar ownership, and nonhome ownership). Hole and McArdle only included patients who had undergone a colorectal resection [14]. Using the Carstairs index, they showed no significant difference in the mode or stage of $\mathrm{CRC}$ at presentation amongst different socioeconomic groups. We could not use the Carstairs and Morris index [22] as it is based on Scottish census data and was designed for use in Scotland. We opted to use the IMD 2010 score in our study as it is a very reliable indicator of deprivation, employs more variables (7 domains compared to 4 in the Townsend score), and is updated every 5 years. The IMD 2010 score has become widely accepted and is used by the government to decide on health policies and distribution of health resources. Of paramount importance is an understanding of the limitations of the various measures of social deprivation as those measures give a general assessment of a geographical area and, therefore, are not specific to the assessment of the deprivation of an individual.

Our study has the advantage of including all newly diagnosed colorectal patients in our study population, unlike the studies of Hole and McArdle [14] and Smith et al. [15] who opted to include only CRC patients who had undergone a resection. We feel this makes our study a true representation of the population; in addition, we used a well-validated, regularly updated measure of deprivation with more variables. Recent studies $[10,18]$ carried out in the US amongst deprived populations have the advantage of a large study cohort; however, the authors of those studies have acknowledged that the use of Medicare insurance data raises the question of accuracy. In addition, no deprivation score was used for statistical analysis.

In conclusion, using a different measure to assess deprivation, our study suggests an association between deprivation and the stage of presentation of CRC. It also suggests that patients undergoing emergency surgery have a higher 90-day mortality rate, although this was not found to be related to deprivation. The longterm effects of social deprivation as an independent risk factor on CRC outcomes requires further research. This study also highlights the need for the development of a measure to assess social deprivation on an individual basis.

\section{CONFLICT OF INTEREST}

No potential conflict of interest relevant to this article was reported.

\section{REFERENCES}

1. Holleczek B, Rossi S, Domenic A, Innos K, Minicozzi P, Francisci $S$, et al. On-going improvement and persistent differences in the survival for patients with colon and rectum cancer across Europe 1999-2007 - Results from the EUROCARE-5 study. Eur J Cancer 2015;51:2158-68.

2. Moghimi-Dehkordi B, Safaee A. An overview of colorectal cancer survival rates and prognosis in Asia. World J Gastrointest Oncol 2012;4:71-5.

3. SEER Cancer Statistics Review, 1975-2012 [Internet]. Bethesda (MD): National Cancer Institute; 2014 [cited 2015 Apr 1]. Available from: http://seer.cancer.gov/statfacts/html/colorect.html.

4. Health and Social Care Information Centre. National Bowel Cancer Audit Report 2014. Leeds (UK): NHS Digital; 2014.

5. McArdle CS, Hole DJ. Emergency presentation of colorectal cancer is associated with poor 5-year survival. Br J Surg 2004;91:605-9. 
6. Cuffy M, Abir F, Audisio RA, Longo WE. Colorectal cancer presenting as surgical emergencies. Surg Oncol 2004;13:149-57.

7. Bass G, Fleming C, Conneely J, Martin Z, Mealy K. Emergency first presentation of colorectal cancer predicts significantly poorer outcomes: a review of 356 consecutive Irish patients. Dis Colon Rectum 2009;52:678-84.

8. Chow CJ, Al-Refaie WB, Abraham A, Markin A, Zhong W, Rothenberger DA, et al. Does patient rurality predict quality colon cancer care?: a population-based study. Dis Colon Rectum 2015;58:415-22.

9. Jestin P, Nilsson J, Heurgren M, Påhlman L, Glimelius B, Gunnarsson U. Emergency surgery for colonic cancer in a defined population. Br J Surg 2005;92:94-100.

10. Elliss-Brookes L, McPhail S, Ives A, Greenslade M, Shelton J, Hiom S, et al. Routes to diagnosis for cancer - determining the patient journey using multiple routine data sets. Br J Cancer 2012; 107:1220-6.

11. Iversen LH, Bülow S, Christensen IJ, Laurberg S, Harling H; Danish Colorectal Cancer Group. Postoperative medical complications are the main cause of early death after emergency surgery for colonic cancer. Br J Surg 2008;95:1012-9.

12. Paulson EC, Mahmoud NN, Wirtalla C, Armstrong K. Acuity and survival in colon cancer surgery. Dis Colon Rectum 2010; 53:385-92.

13. Diggs JC, Xu F, Diaz M, Cooper GS, Koroukian SM. Failure to screen: predictors and burden of emergency colorectal cancer resection. Am J Manag Care 2007;13:157-64.

14. Hole DJ, McArdle CS. Impact of socioeconomic deprivation on outcome after surgery for colorectal cancer. Br J Surg 2002;89: 586-90.

15. Smith JJ, Tilney HS, Heriot AG, Darzi AW, Forbes H, Thompson $\mathrm{MR}$, et al. Social deprivation and outcomes in colorectal cancer. Br J Surg 2006;93:1123-31.

16. Pruitt SL, Davidson NO, Gupta S, Yan Y, Schootman M. Missed opportunities: racial and neighborhood socioeconomic disparities in emergency colorectal cancer diagnosis and surgery. BMC Cancer 2014;14:927.

17. Centers for Disease Control and Prevention (CDC). Cancer screening - United States, 2010. MMWR Morb Mortal Wkly Rep 2012;61:41-5.

18. Shapiro JA, Klabunde CN, Thompson TD, Nadel MR, Seeff LC, White A. Patterns of colorectal cancer test use, including CT colonography, in the 2010 National Health Interview Survey. Cancer Epidemiol Biomarkers Prev 2012;21:895-904.

19. Lansdorp-Vogelaar I, Kuntz KM, Knudsen AB, van Ballegooijen M, Zauber AG, Jemal A. Contribution of screening and survival differences to racial disparities in colorectal cancer rates. Cancer Epidemiol Biomarkers Prev 2012;21:728-36.

20. Department for Communities and Local Government. The English Indices of Deprivation 2010. London: Department for Communities and Local Government; 2011.

21. Townsend P, Phillimore P, Beattie A. Health and deprivation: inequality and the North. London: Croom Helm; 1988.

22. Carstairs V, Morris R. Deprivation: explaining differences in mortality between Scotland and England and Wales. BMJ 1989; 299:886-9. 